\section{THE -109C>T POLYMORPHISM OF THE FCER1B GENE IN CHILDREN WITH ASTHMA}

\section{Tikhonova, A. Voitovich, D. Korostovsev, V. Larionova \\ Saint-Petersburg State Pediatric Medical Academy, St.-Petersburg, Russia}

Among the genes predisposing individuals to atopy, several variants of the FCER1B gene were reported to associate with atopic asthma. One of them, a substitution of cytosine to thymine at position 109 in promoter region of the FCER1B gene has been shown to be associated with total IgE levels.

The aim: To investigate genotype and allele distribution of the FCER1B gene polymorphism in children with asthma.

Study groups: Children with mild asthma ( 72 boys and 10 girls), children with severe asthma (42 boys and 16 girls) aged $3-17$ years old.

Controls: 136 healthy children (65 boys and 71 girls) aged 4-17 years old. The $-109 \mathrm{C}>\mathrm{T}$ polymorphism was identified by PCR-RFLP. The data was compared with Chi-square test.

Results: Genotype and allele distribution in asthmatic subjects and controls are presented in the table 1

\begin{tabular}{|c|c|c|c|c|}
\hline & \multicolumn{2}{|c|}{ Study group (140) } & \multicolumn{2}{c|}{ Control group (136) } \\
\hline $\begin{array}{c}\text { Geno- } \\
\text { types }\end{array}$ & $\begin{array}{c}\text { boys } \\
114(81 \%)\end{array}$ & $\begin{array}{c}\text { girls } \\
26(19 \%)\end{array}$ & $\begin{array}{c}\text { boys } \\
71(52 \%)\end{array}$ & $\begin{array}{c}\text { girls } \\
65(48 \%)\end{array}$ \\
\hline CC & $15 \%$ & $3 \%$ & $14 \%$ & $12 \%$ \\
\hline CT & $46 \%$ & $62 \%$ & $47 \%$ & $56 \%$ \\
\hline TT & $39 \%$ & $35 \%$ & $39 \%$ & $32 \%$ \\
\hline C & $38 \%$ & $35 \%$ & $37 \%$ & $40 \%$ \\
\hline T & $62 \%$ & $65 \%$ & $63 \%$ & $60 \%$ \\
\hline
\end{tabular}

[Table 1.]

Conclusion: There were no significant differences in genotype and allele distribution in affected children according to their sex and severity of the disease. Both allele and genotype distribution of the FCER1Bgene polymorphism were similar in asthmatic subjects and in controls, being in line with previously reported data.

\section{DETECTING THE SINGLE NUCLEOTIDE POLYMORPHISMS AND METABOLIC PHENOTYPE OF CYTOCHROME P450 GENES IN CHINESE HAN POPULATION}
A.D. Shen ${ }^{1,2}$, J. $\mathrm{Xiao}^{3}$, Y. Gu ${ }^{3}$, L. Sun ${ }^{3}$, Q. $\mathrm{MiaO}^{3}$
${ }^{1}$ Microbiology and Immunology, Beijing
Children's Hospital, Affiliated to Capital Medical
University, ${ }^{2}$ Beijing Pediatric Research Institute,
${ }^{3}$ Molecularbiology and Immunology, Beijing
Children's Hospital, Affiliated to Capital Medical
University, Beijing, China

Objective: The aim of this study was to understand the genetic polymorphism of CYP450 subtypes, and to obtain the genetic data of these loci in Chinese Han population.

Methods: We identified 300 children who were randomly sampled from the outpatient and inpatient department from March, 2005 to December, 2008. Members of these children were of Chinese Han ancestry. Eight important SNPs in 6 important CYP450 subtypes (CYP2E1 -1053C>T, CYP3A4 878T >C, CYP2D6 100C>T, CYP2C9 1075A >C, CYP2E1 7632T>A, CYP2C19 636G>A, CYP2C19 $681 \mathrm{G}>\mathrm{A} / \mathrm{C}$ and CYP3A5 6986A>G) were chosen for this study. The genotypes of these SNPs in 300 random Chinese Han children were typed by realtime PCR and by sequencing.

Results: The frequencies of wild heterozygote on the loci of CYP2D6 100C>T, CYP2C19 681G>A/C and CYP3A5 6986A>G $(0.470,0.463$ and 0.437$)$ were high in Chinese Han population, and the frequencies of mutant homozygote on the loci of CYP2D6 and CYP3A5 were higher than that of wild homozygote $(0.353$ vs $0.177,0.417$ vs 0.147$)$. The frequencies of wild homozygote on the loci of CYP2C9 1075A $>C$, CYP3A4 878T >C, CYP2C19 636G >A, CYP2E1 -1053C>T and CYP2E1 7632T>A $(1.000,0.980,0.893,0.613$ and 0.583$)$ were high in Chinese Han population, the genetic variability on the loci of CYP2C9 1075A>C and CYP3A4 878T>C $(0.000,0.020)$ were especially rare in Chinese Han population.

Conclusions: The mutation frequencies of these three SNPs (CYP2D6 100C>T, CYP2C19 681G $>A / C$ and CYP3A5 6986A>G) were high in random Chinese Han population, so they could be candidate loci for subsequent optimization grouping SNPs research. 